\title{
A constituição da demanda para a Neurologia a partir da Educação
}

\section{The constitution of the demand for neurology referrals from within education}

\section{La constitución de la demanda para la neurología a partir de la educación}

\author{
Ricardo Arantes ${ }^{1}$ \\ Claudia Freitas ${ }^{1}$
}

DOI: http://dx.doi.org/10.20435/serie-estudos.v24i51.1217

\begin{abstract}
Resumo: O presente texto é resultado de uma pesquisa que investiga a constituição da demanda para a Neurologia a partir da solicitada pela Educação utilizando elementos quantitativos e discursivos. Propõe-se o termo neurocolonização - em que os saberes das neurociências-pesquisa seriam fundamentais à otimização do ensino - e revisita-se o tema da medicalização na Educação, problematizando a prática de compreender o não aprendizado como falha do/no corpo do sujeito. Como estratégia metodológica, foi feito o levantamento dos encaminhamentos realizados num município da Grande Porto Alegre, RS durante o segundo semestre de 2015 e a análise de documentos escolares anexos a alguns desses encaminhamentos. Os achados indicam que as questões relacionadas à Educação figuram como a principal causa agrupável dentro dessas indicações, superando problemas como epilepsia/convulsões. A leitura desses anexos evidencia inespecificidade das situações-problema e hibridização de modos de olhar a questão das crianças que lançam desafios à escola, onde coexistem demandas por intervenções familiares, por classificações psiquiátricas contemporâneas e incidência de leituras psicologizantes, reproduzindo formas de medicalização e seus desdobramentos de medicamentalização e patologização.
\end{abstract}

Palavras-chave: Medicalização; encaminhamentos a Neurologia; educação especial; inclusão escolar

\begin{abstract}
This article discusses the constitution of the demand for Neurology referrals from within Education using quantitative and qualitative means. The expression neurocolonization is proposed to describe situations whenever neurosciences underpine teaching optimization processes. Medicalization on Education is reviewed in order to problematize the comprehension of learning impediments as bodily defects. Neurology referral letters in a city in the metropolitan area of Porto Alegre, RS, during the second semester of year 2015 were mapped. Six letters written by teachers were found attached to those referrals. Neurology referrals related to educational issues
\end{abstract}

\footnotetext{
${ }^{1}$ Universidade Federal do Rio Grande do Sul (UFRGS), Porto Alegre, Rio Grande do Sul, Brasil.
} 
outnumber complaints as headaches and epilepsy/convulsions. Situations reported in the six letters reveal inespecificity of questions addressed and hybridization of modes of understanding of children who do not fit in school, combining demands for familial interventions, contemporary psychiatric diagnoses and psychologization processes, reproducing medicalization practices and consequently pharmacologization and pathologization.

Keywords: Medicalization; Neurology referrals; specialized education; school inclusion.

Resumen: El presente texto, evidencia los resultados de una investigación que tiene como objeto mostrar la constitución de los requerimientos para Neurología solicitados por la Educación, a partir de elementos cuantitativos y discursivos. Se propone el termino neurocolonización, entendido como el lugar donde los saberes de la neurociencia serian fundamentales en el progreso de la enseñanza, con la finalidad de comprender lo aprendido o no como defecto en el sujeto, igualmente se revisara el tema de la medicalización en la educación. Como estrategia metodológica se realizó el levantamiento de las remisiones realizadas en el municipio da Grande Porto Alegre, RS, y el análisis de los documentos escolares que se encontraban anexos a algunas de estas remisiones. Los documentos encontrados indican que los problemas relacionados a la educación figuran como la principal causa asociada dentro de estas indicaciones, superando problemas como la epilepsia/ convulsiones. La lectura de estas remisiones evidencia poca especificidad en la manera de observar las situaciones problema e hibridación de los niños y niñas, convirtiéndolas en un desafío para la escuela donde coexisten demandas por intervenciones familiares, por clasificaciones psiquiátricas contemporáneas, así como la incidencia de lecturas respecto a la psicologización, reproduciendo formas de medicalización y sus progresos respecto a medicamentalización y patologización.

Palabras clave: medicalización; Neurología; remisiones a neurología; Neurocolonización; educación especial.

\section{INTRODUÇÃO}

"Provável Síndrome de Tourette

- Tiques

- Obsessivo-compulsivo

- T.D.A.H

- Impulsividade

- Dist. Oposicional Desafiante"

(Médico neurologista, fevereiro de 2017)

Essa lista de classificações diagnósticas e sintomas psíquicos, manuscrita por um neurologista infantil num município da Grande Porto Alegre, RS, foi objeto de uma discussão de caso clínico entre a equipe de uma unidade básica de saúde e alguns trabalhadores de um Centro de Atenção Psicossocial para crianças e adolescentes no mesmo município. Este outro fragmento de um documento guarda relação direta com a lista acima: 
Solicitamos o encaminhamento ao pediatra para solicitação de avaliação neurológica do George ${ }^{2}[\ldots]$ sendo que observamos questões relativas à aprendizagem e linguagem. (Documento da escola, dezembro de 2014).

Observamos um intervalo de mais de dois anos entre a "solicitação de avaliação neurológica" e a lista de exuberante nosologia. Situações semelhantes a esta têm sido frequentes e vão desenhando esses descompassos, nos quais os encaminhamentos para a Neurologia advindos da Educação submergem essas crianças.

O tema central deste artigo é forjado em problematizar os processos de medicalização engendrados nos encaminhamentos à Neurologia, em que a Educação exerce um papel protagonista. Definimos como direção da pesquisa analisar o levantamento feito sobre os encaminhamentos para a Neurologia, com destaque para elementos que remetem ao campo da Educação. Esse tipo de situação hoje configura-se como o principal motivo classificável de encaminhamento de crianças e adolescentes para a Neurologia. Revisitamos leituras sobre a interferência de discursos oriundos das neurociências sobre a Educação e sobre os processos de medicalização da Educação, a partir de autores brasileiros e estrangeiros. A análise dos textos dos encaminhamentos e a coexistência de documentos originados na escola anexados a eles nos ajudaram a reconhecer peculiaridades na constituição dessa demanda.

\section{PECULIARIDADES SOBRE OS MODOS DE SE OPERAR POLÍTICAS PÚBLICAS EM SAÚDE E EDUCAÇÃO NO CONTEXTO-CENÁRIO}

Algumas peculiaridades sobre as políticas públicas em Saúde e Educação no município lócus da pesquisa aqui desenvolvida ajudam a contextualizar o percurso metodológico e os achados recolhidos nesta trajetória.

Experiências iniciadas há cerca de vinte anos pelas primeiras equipes de psicólogos dentro da Educação deixaram como legado as chamadas reuniões de rede. Hoje capilarizadas pelos territórios e fortalecidas por parcerias consistentes, essas reuniões reúnem mensalmente técnicos ligados a serviços estatais e trabaIhadores ligados a associações de moradores, organizações da sociedade civil etc. Das reuniões de rede também são disparados encontros de microrredes, arranjos

\footnotetext{
2 Nome fictício.
} 
dinâmicos de profissionais de diferentes equipes em torno de alguma situação grave envolvendo crianças, adolescentes e seus cuidadores. Esses dispositivos demandam de seus atores mais do que conhecimento científico ou embasamento técnico: exigem sistematicamente articulações e (re)negociações, convidando a um repensar constante das práticas cotidianas à luz das principais políticas públicas dirigidas às crianças e aos adolescentes.

Essas estratégias, entretanto, distanciam-se do que o município em tela oferta em termos de cuidados em saúde dentro da especialidade neuropediatria. Opera aqui um modo anacrônico centrado em dois tipos de lógicas. A primeira é a da terceirização, ou seja, a contratação de uma empresa prestadora de serviço à qual são subordinados profissionais médicos. Em consonância com a terceirização, faz-se presente a lógica ambulatorial, por meio da qual as intervenções sobre os processos saúde-doença (essencialmente consultas e exames) são sequenciais e desarticuladas dos outros pontos de atenção à saúde. A combinação entre essas duas lógicas produz distanciamento entre a dinâmica do trabalho em rede e as intervenções dos profissionais neurologistas, de quem se demandam classificações diagnósticas e intervenções frequentemente medicamentosas.

\section{NEUROCOLONIZAÇÃO E MEDICALIZAÇÃO NA EDUCAÇÃO: LENTES TEÓRICAS}

Tendo como o objetivo central deste artigo levantar elementos quantitativos e discursivos que ajudem a compreender a constituição da demanda para a Neurologia a partir da Educação, propomos dois balizadores teóricos. O primeiro deles chamamos neurocolonização, que denuncia o insistente recurso aos saberes das neurociências-pesquisa pela Educação, como se os conhecimentos acerca do funcionamento do cérebro fossem fundamentais e imprescindíveis ao professor. O segundo balizador remete aos processos de medicalização da Educação, que operam na dimensão micropolítica, sobretudo nesse movimento dos professores demandando respostas do especialista-clínico para situações individuais.

\subsection{Neurociências colonizando a Educação}

A neurocolonização da Educação é observada sobretudo a partir dos anos 1990, quando se observa, sobretudo nos países ocidentais, uma crescente 
capitalização das pesquisas em torno da materialidade cerebral (financiadas pela corporação médica, academia e indústria tecnológica) e do surgimento de uma série de iniciativas e organizações que prometiam revolucionar o universo do ensino e aprendizagem, geralmente de uma maneira hiperbólica (PYKETT; DISNEY, 2015). Esse movimento se empenha em se propor como única fonte adequada de explicação dentro do campo da Educação, situando as neurociências como evidência fundante para os processos de ensino e aprendizagem.

Entendemos ser importante evitar a ideia de colonização pressupondo um lugar passivo da Educação, num falso binômio educação fraca/neurociência forte (DE VOS, 2015). Parece sensato supor um papel protagonista da Educação nesse processo de ressignificação dos saberes escolares. Santos enfatiza:

estamos passando por um momento em que os saberes escolares estão sendo ressignificados a partir das verdades das neurociências contemporâneas e que isso tem efeitos concretos nos sujeitos escolares - mas não apenas neles, pois se trata de um processo social mais amplo, no qual todos nós, de um modo ou de outro, como pais, professores/as e pessoas deste mundo, estamos envolvidos nestas formas "cerebrais/farmacológicas" de ligar com aquilo que pensamos ser. (SANTOS, 2012, p. 198).

Richter (2012), ao elaborar uma revisão de uma década sobre a revista Nova Escola, levanta evidências da considerável permeabilidade com que o discurso das neurociências tem penetrado os enunciados a respeito dos processos de ensino-aprendizagem. Nas publicações entre 2000 e 2010, há uma ascensão das concepções cerebralistas na direção de explicar as várias manifestações comportamentais dos alunos, sobretudo as 'indesejadas'. O cérebro passa a ser o protagonista de inúmeras ações, comportamentos e processos de memória, de aprendizado e de concentração.

Ao analisarmos o conceito de "imaginários", de Rose e Abi-Rached (2013), o consideramos bastante estratégico aqui para pensar as diferentes vertentes epistemológicas envolvidas nessas operações de redução do aprendizado à atividade cerebral. Esses imaginários têm a função de construir as pontes entre as pesquisas cerebrais em laboratório ao mundo cotidiano, como se trilhassem os caminhos da mente em direção ao cérebro. Conforme os autores, o "imaginário visualizável" trabalha dentro da perspectiva de que aparatos tecnológicos possibilitariam observar a mente em funcionamento, disseminando o recurso a esses equipamentos como ferramentas de pesquisa, resultando em milhares de artigos 
publicados (em 2011 eram cerca de 600 publicações por mês). Muitas dessas publicações alegam supostamente ter identificado correlatos neuronais de uma gama de experiências e estados mentais humanos: "amor, ódio, afetações pela literatura e até a fidelidade político-partidária” (ROSE; ABI-RACHED, 2013, p. 26). Não obstante a notoriedade de seus problemas técnicos, limitações e premissas, esse "imaginário" mantém seu poder de persuasão, influenciando áreas que vão do neuromarketing às políticas de desenvolvimento infantil.

A crença em podermos "ver" a mente no cérebro vivo e mesmo observar as paixões e seus desejos que aparentemente estão por trás das crenças, emoções e comportamentos - tanto normais quanto patológicos - tem sido um elemento-chave para a afirmação de que as neurociências podem fornecer informações úteis para o governamento dos humanos e para "conduzir-lhes a conduta" no mundo cotidiano. (ROSE; ABI-RACHED, 2013, p. 25, tradução do autor).

As pontes entre neurociências e Educação frequentemente recorrem a operações de redução da aprendizagem a fenômenos cerebrais em diferentes mat( $r$ ) izes e nuances. Uma das principais estratégias para essa sustentação implica a adesão ao programa cognitivista do aprendizado enquanto disciplina mediadora (PYKETT; DISNEY, 2015).

\subsection{Processos de medicalização na Educação}

As leituras contemporâneas e suas revisões sinalizam que, mais que um conceito, a noção de medicalização precisa ser tomada a partir de seus processos de engendramento, que operam por meio de inúmeras estratégias e tecnologias que transcendem a prescrição de medicamentos. Zorzanelli et al. (2014) denunciam os riscos do desgaste do uso do termo e a consequente perda de sua acurácia teórica, reconhecendo também que tais processos são marcados por anomalias, variabilidades e desigualdades, incluindo a possibilidade de desmedicalização, ou seja, de que os comportamentos, práticas ou intervenções medicalizados saiam do alcance da jurisdição médica.

Rose (2007) reconhece a permeabilidade dos processos de medicalização sobre diferentes dimensões de nossas vidas, desde os hábitos mais automatizados (como escovar os dentes ou usar talheres), viabilizando o crescimento populacional e a vida nas grandes cidades, e reduzindo a mortalidade por meio das vacinações 
e do enfrentamento de epidemias. O autor destaca que o saber médico também está tão imbricado na nossa forma de experimentar e dar sentido ao mundo, que atravessa até mesmo as relações entre significante e significado.

As lentes genealógicas sobre os processos de medicalização no Brasil fazem ver, na obra de Costa (1979), os primeiros rastros quando da transição de um Brasil colonial para uma nação urbanizada, momento no qual a medicina encontra um lócus privilegiado na disputa entre o Estado colonial e o poder das famílias detentoras de terras. Uma série de barreiras à higienização das cidades era sistematicamente imposta pelos hábitos bastante peculiares das famílias tradicionais, cabendo à recém-emergente corporação médica (dotada de embasamento empírico e conceitual mais consistente) a tarefa de oferecer alternativas à tradição punitiva da legalidade colonial e implementar uma infinidade de estratégias higienistas. A expansão quantitativa das instituições escolares, com a chegada da família real ao Brasil, produz, a partir da aliança medicina-escola, um vetor de proliferação das teses higienistas, apropriando-se das crianças, separando-as dos pais e, em seguida, devolvendo-as às famílias convertidas em soldados da saúde.

O conjunto de interesses médico-estatais interpôs-se entre a família e a criança, transformando a natureza e representação desta última. As sucessivas gerações formadas por essa pedagogia higienizada produziram o indivíduo urbano típico no nosso tempo. (COSTA, 1979, p. 214).

Ainda no cenário brasileiro, a crítica aos processos de medicalização na Educação recebeu importante contribuição de Moysés (2001; 2008), denunciando a transformação de um mundo social e historicamente construído em objeto biológico e a redução da essência da historicidade do objeto - a diferença e o questionamento - a características inatas, a uma patologia.

Ao estender seu campo de atuação ao ambiente escolar, a medicina passa a atuar sobre esse ambiente segundo sua própria concepção. Ao normatizar preceitos para a aprendizagem adequada, estende-se para o não-aprender. Medicaliza a educação, transformando os problemas pedagógicos e políticos em questões biológicas, médicas. Cria as entidades nosológicas das doenças do não-aprender-na-escola e para elas propõe solução. Antecipando-se, prevê que os problemas irão ocorrer e se coloca como portadora das soluções. (MOYSÉS, 2001, p. 190).

Moysés relaciona os processos de medicalização na Educação à insistência em se reduzir questões pertinentes à coletividade - a vida na escola, a vida do 
professor e das famílias, os circuitos de produção de vida ou de adoecimento em cada escola - a uma dimensão individual. Assim, não resta outro olhar possível para explicar o não aprendizado senão o que vê tão somente uma falha do/no corpo do sujeito não aprendente, turvando as possibilidades de se olhar para o contexto onde o não-aprender-na-escola se desdobra. Angelucci (2015) problematiza ainda a procura de educadores(as) por cursos que os instrumentalizem a partir de conceitos inerentes às Ciências da Saúde e façam incidir o foco sobre as patologias de desenvolvimento, como se o domínio das condições patológicas fosse exigência sine qua non para o estabelecimento de um projeto educacional.

Os processos de medicalização também podem ser compreendidos para além da dimensão de um controle central e vertical sobre as vidas, onde o poder emana essencialmente da corporação médica. Olhemos, assim, para esses processos de outra maneira, tomando-os enquanto

[...] práticas [que] conduzem, movimentam, se espalham, funcionam como uma maquinaria social que não está situada em um lugar e se dissemina por toda a estrutura social. Os saberes médicos foram historicamente produzindo discursos, resistências, formas de saber e de poder [...]. Esse movimento da medicalização na vida social torna visível a ação do dispositivo na vida de cada um e de todos. Um dispositivo constituído de linhas que transitam, se conectam, se relacionam inventando modos de viver. (CHRISTOFARI; FREITAS; BAPTISTA, 2015, p. 1085).

Que particularidade encontramos nos processos de medicalização em sua faceta de neurologização aos quais dedicamos o nosso olhar?

\section{METODOLOGIA}

Os primeiros indicadores da dimensão dessa demanda para a Neurologia surgem quando de um encontro com um dos médicos neurologistas neste município, que concede informalmente acesso a um pequeno montante de cartas de referência ${ }^{3}$ das crianças que seriam atendidas naquele dia. Emergem

\footnotetext{
${ }^{3}$ Cartas de referência e contra-referência (popularmente conhecidas como "encaminhamentos", são os documentos escritos por um médico 'não especialista', dirigidos a um especialista - referência - que teoricamente responderá indicando sua impressão e orientando a conduta contra-referência). Para que possam ter acesso a uma consulta neurológica, os responsáveis pela criança ou adolescente precisam apresentar esta carta de referência à central de marcação de consultas localizada na Secretaria Municipal de Saúde do município onde foi realizado o estudo.
} 
dali muitas vozes: a dos profissionais que assinam o encaminhamento, a dos professores e a dos familiares. Os termos ligados ao campo da Educação eram frequentes nas curtas frases que buscavam justificar o convite a uma intervenção neurológica.

A partir de uma autorização formal solicitada à Secretaria de Saúde, foi possível ter acesso integral e ampliado às cartas de referência à Neurologia, que foram acessadas em uma única sessão de leitura em fevereiro de 2016. Foram registrados os elementos fundamentais (bairro, idade, motivo, unidade encaminhadora) de cada carta, além de registro fotográfico daquelas nas quais havia menção a termos relacionados ao campo da Educação. A sistematização foi feita com auxílio do aplicativo Microsoft Excel ${ }^{\circledast}$, e empregou-se uma análise matemática simplificada (totalizações e porcentagens) como forma de construção das macrocategorias analisadas. Efetuou-se de igual maneira a seleção e transcrição de trechos contendo referência aos temas educacionais.

Desdobra-se como produto um recorte quantitativo, um modo de olhar sobre o que perpassa essas interferências à vida de cada um daqueles aprendentes-sujeitos e uma análise qualitativa preliminar de fragmentos de alguns documentos encontrados, conforme detalhado a seguir.

\section{RESULTADOS: “ENCAMINHAMENTOS EDUCACIONAIS" PARA A NEUROLOGIA}

A partir de um total de 800 cartas de referência, que também incluíam encaminhamentos de adultos, selecionamos e analisamos 203 cartas indicando somente aqueles tratando de crianças e adolescentes ${ }^{4}$, no segundo semestre de $2015^{5}$. Agrupamos inicialmente as justificativas para os encaminhamentos em duas macrocategorias, de acordo com a existência ou não, dentro dessas justificativas, de menção a algum elemento relacionado a escola, aprendizado, leitura, escrita ou termos familiares ao campo da Educação. Emergem, dessa forma, as macrocategorias 'Encaminhamentos Educacionais' (na qual houve menção a

\footnotetext{
${ }^{4}$ Entre zero e 17 anos.

${ }^{5}$ Tivemos acesso aos encaminhamentos realizados em dois intervalos distintos: o mês de julho de 2015 e o intervalo entre outubro e dezembro do mesmo ano.
} 
termos relacionados ao campo da Educação) e 'Encaminhamentos Clínicos' ${ }^{6}$ (na qual não houve essa menção). O Quadro 1 resume esses achados.

Quadro 1 - Resumo dos encaminhamentos à Neurologia

\begin{tabular}{lc}
\hline \multicolumn{2}{c}{ Resumo dos encaminhamentos à Neurologia } \\
\hline Encaminhamentos (adultos, crianças e adolescentes) & 800 \\
Encaminhamentos de crianças e adolescentes & 203 \\
'Encaminhamentos clínicos' & 125 \\
Cefaleia & 31 \\
Epilepsia/convulsões & 29 \\
Outros & 64 \\
'Encaminhamentos educacionais' & 65 \\
Inclui menção a TDA/H ou hiperatividade & 26 \\
Não inclui menção a TDA/H ou hiperatividade & 39 \\
\hline
\end{tabular}

Fonte: Elaboração própria.

Das 203 cartas relacionadas a crianças e adolescentes, agrupamos 125 como 'Encaminhamentos Clínicos', nos quais se destacam numericamente duas subcategorias: 'cefaleia' (31 casos) e 'convulsões e/ou epilepsia' (29 casos). As cartas restantes trazem uma gama de situações de baixa frequência ou especificidade?, que produziriam uma dispersão desnecessária na presente análise. Em 13 casos, a justificativa não pôde ser reconhecida (por ser ilegível ou conter informações insuficientes).

Na macrocategoria 'Encaminhamentos Educacionais' (65 cartas de referência), duas subcategorias são criadas tendo como critério a existência ou não de termos relacionados a 'hiperatividade' e hipóteses diagnósticas de TDA/H, haja vista este sintoma/queixa/problema ser o mais frequente na interface entre Educação e o campo da Saúde Mental Infanto-juvenil. (GOODMAN; SCOTT, 2004; LAURIDSEN-RIBEIRO; TANAKA, 2005; SANTOS; FREITAS, 2016). Curiosamente, a quantidade de menções diretas ou indiretas à classificação diagnóstica de TDA/H

\footnotetext{
"Optamos por reduzir aqui o termo "clínico" para a dimensão da clínica médica/"não mental" como forma de organização dos achados.

${ }^{7}$ Como exemplo: autismo, alterações de exames complementares sem menção a queixas clínicas, "paralisia cerebral" etc.
} 
ou ao sintoma hiperatividade $(n=26)$ é menor do que aquela encontrada no grupo em que não há este tipo de justificativa (n=39). Neste último, os termos para justificar o encaminhamento são "atraso escolar", "déficit de aprendizado", "déficit de alfabetização", "transtorno de aprendizagem", "não consegue fixar aprendizagem".

Essa análise quantitativa evidencia a demanda para a Neurologia a partir da Educação, materializada sobretudo na superioridade numérica dos "encaminhamentos educacionais" em comparação com a soma das duas causas clínicas mais frequentes (cefaleia e epilepsia), situações na qual a atuação do neurologista é de fundamental importância.

\section{LETRAS-PALAVRAS DAS ENSINANTES: FRAGMENTOS E PISTAS PARA A CONSTITUIÇÃO DA DEMANDA}

O que essas "cartas" (de referência) dizem sobre estes sujeitos descabentes? "Não aprendem, não respeitam, brigam, batem". "A pedido da escola", "professor solicitou encaminhamento". Seis documentos escolares ${ }^{8}$ foram encontrados anexados às cartas de referência, tomados por nós como materialidade do protagonismo de professores no encaminhamento para a Neurologia. Destacamos fragmentos que nos oferecem possibilidades de leituras do processo de constituição dessa demanda.

Documento 1: Já é o segundo encaminhamento solicitado pela Escola para especialista em Neuropediatria. O aluno tem diagnóstico de TDA/H e nunca realizou tratamento. Tem a aprendizagem e a socialização comprometidos em razão do déficit de atenção. (grifo nosso).

Documento 2: Desde muito pequeno sempre se mostrou com grande inquietude, extremamente agitado. Já realizamos várias intervenções com a família a fim de realizar combinações a cerca [sic] de sua rotina e de seus relacionamentos. Já há algum tempo estamos notando um avanço nessa inquietação, o menino tem se tornado bastante agressivo, muitas vezes batendo com muita raiva até mesmo na professora. Com bastante frequência chora, grita e se joga no chão, machucando-se em alguns momentos. (itálico nosso).

\footnotetext{
${ }^{8}$ Dois pareceres descritivos, duas "solicitações de encaminhamento", uma carta e um documento dirigido ao "Pacto Pela Aprendizagem", projeto municipal que visava garantir através de "atendimento" às crianças que deles necessitavam uma diminuição no quantitativo de reprovações.
} 
Documento 3: Solicitamos intervenção, diagnóstico do aluno John ${ }^{9}$, pois o mesmo apresenta algumas dificuldades na escola, como: falta de atenção, agitação, falta de limites nas suas atitudes e nas relações interpessoais. (itálico nosso).

O aluno distrai-se com muita facilidade ao realizar alguma atividade solicitada pela professora. Não está conseguindo se ater por mais tempo em algum trabalho, permanecer sentado no seu lugar. Desta forma não está conseguindo avançar nas aprendizagens.

Em alguns momentos cria conflitos na turma de colegas.

Costuma falar muito alto e nem sempre dá atenção para as ordens da professora. Às vezes fala sobre coisas que aconteceram, mas na verdade são fantasias que cria. (itálico nosso).

Inicialmente, não houve nos fragmentos aqui trazidos termos que remetessem ou fizessem supor um recurso aos saberes das neurociências-pesquisa, de modo que nos é possível afirmar que o processo de neurocolonização não se fez presente nos achados recolhidos durante os passos metodológicos. Não foram encontradas, igualmente, evidências da considerável permeabilidade com que os enunciados das neurociências têm penetrado teorias e práticas de ensino-aprendizagem (RICHTER, 2012).

Os destaques em negrito nas transcrições dos documentos 1 e 3 indicam um hibridismo que inclui termos relacionados ao campo da Psicologia e uma relação causal entre "déficit de atenção" e dificuldades de aprendizagem e socialização. Tal observação aproxima-se do processo de transição de uma psicologização para uma neurologização da Educação, como descrito por Jan de Vos (2015). O autor sugere que a Psicologia, mesmo tendo operado um discurso poderoso e invasivo sobre a Educação, não conseguiu dar conta daquilo que não funciona e falha ao tentar explicar aquilo que frustra seus ideais humanistas. O discurso psi enfrenta dificuldades em pensar as falhas na psique em seus próprios termos, e isso parece ser o combustível do recurso ao neurológico.

O documento 2 evidencia uma interferência sobre a dinâmica familiar "a fim de realizar combinações a cerca [sic] de sua rotina e de seus relacionamentos", em consonância com o trabalho de Costa (1979) e Donzelot (2005) abordando as estratégias utilizadas pelo Estado moderno para exercer o controle junto às famílias, buscando disciplinar a prática anárquica da concepção e cuidado físico dos filhos.

\footnotetext{
${ }^{9}$ Nome fictício.
} 
Duas estratégias são operadas nesse movimento: a primeira delas no interior das famílias burguesas, reorganizando-as em torno da conservação e educação das crianças, e naquelas mais pobres sob a forma de campanhas de moralização e higiene da coletividade. Essa aliança medicina-escola através da higiene familiar é, segundo Costa (1979), um elemento importante na série de medidas normalizadoras em busca de organizar a sociedade desde o início do século XX.

Dessa forma, podemos considerar que as justificativas para se encaminhar uma criança descabente a um 'médico especialista no cérebro' falam de um processo de aggionarmento (CASTEL, 1978), ou seja, de uma atualização constante de suas dinâmicas, contornos e configurações, ao mesmo tempo em que dá continuidade à tradição secular dos primórdios da constituição do estado brasileiro, a partir da aliança estado-medicina-escola.

Apesar de os encaminhamentos para a Neurologia serem o problema disparador deste trabalho, reconhecemos uma série de atravessamentos que remetem a temas ligados à Psiquiatria, seja na escolha do referencial teórico que se apoia em autores mais próximos (e críticos) do campo da Psiquiatria, seja nos termos do fragmento do documento inicial deste artigo. Psiquiatria e Neurologia infantis compartilham largas áreas de sobreposição nas intervenções operadas sobre os corpos e nas verdades sobre os sujeitos que se autorizam a enunciar, o que nos permite pegar de empréstimo a expressão cunhada por Surjus e Campos (2013) para propor que a fronteira entre esses dois campos se transformou em um território.

Uma lente cronológica linear sobre a essa fronteira-território nos mostra que a clínica neurológica se organiza posteriormente à Psiquiatria. Dito de outro modo, a descoberta das relações entre localização e função cerebral pela Neurologiaciência não antecedeu o saber psiquiátrico.

Por um lado, a clínica psiquiátrica já era muito completa, no momento em que a clínica neurológica estava no limbo: na metade do século XIX, a semiologia das alucinações ou dos delírios já havia se constituído quase tal qual a utilizamos hoje em dia, ao passo que em 1873 a entrada do cérebro no Dictionnaire Dechambre mencionava como sintomas de afecção cerebral as anomalias do sentimento, do pensamento e da vontade, as alucinações e as ilusões sensoriais, a passividade motora e as convulsões. (LANTERI-LAURA; BOUTTIER, 2000, p. 286).

Outras lentes, por sua vez, convidam-nos a acompanhar Singh (2002) e Caliman (2009) quando evidenciam o estreitamento conceitual que permitiu 
a questão dos 'corpos que não param' (FREITAS, 2011), outrora sob a égide da Psicologia e posteriormente da Neurologia, ser capturada pelo discurso psiquiátrico contemporâneo e seus sistemas diagnósticos, como bem ilustra a transcrição do manuscrito inicial deste artigo. Esse estreitamento incide inicialmente sobre a amplidão do termo 'distúrbio emocional' - inspirado nas teorias psicológicas - até então abrangente o suficiente para dar conta do fenômeno desses aprendentes-desviantes. O segundo passo desse estreitamento propõe a nomenclatura de Doença Cerebral Mínima, ao assumir uma etiologia orgânica para os problemas apresentados pelos descabentes. A escolha por um sintoma específico (a hipercinese) ainda garantia que a questão permanecesse dentro da jurisdição da Neurologia. Na última etapa, a limitação de uma única teoria causal, o déficit de atenção como explicação para a hipercinese, no contexto do DSM IV, remete o universo dessas crianças que desafiam as escolas à intervenção da Psiquiatria (CALIMAN, 2009).

Os achados-palavras recolhidos na leitura das cartas oferecem-nos uma leitura não linear desse processo; ou seja, reconhecemos a convivência entre discursos que se remetem a "distúrbios emocionais" (documentos 2 e 3, destaques em negrito), lançando mão de classificações contemporâneas (documento 1, destaque em sublinhado) e convidando os especialistas no cérebro para intervenções sobre os corpos. Esta não linearidade autoriza-nos, inclusive, a não dar à questão específica do TDA/H a mesma centralidade dos trabalhos de Singh (2002) e Caliman (2009). A demanda para a Neurologia hibridiza a temática dos "corpos que não param" (FREITAS, 2011) com as "crianças que não-aprendem-na-escola" (MOYSÉS, 2001), em uma forma bastante peculiar e preocupante de medicalização da Educação.

\section{CONSIDERAÇÕES FINAIS}

Compreender a constituição da demanda para a Neurologia na Educação a partir de elementos quantitativos e discursivos nos convida a revisitar o tema da medicalização e sua permeabilidade pelo campo da Educação, tomando como elementos de análise as cartas de referência para a Neurologia e fragmentos de documentos utilizados como disparadores desses encaminhamentos. Os temas relacionados à Educação se configuram como a principal causa agrupável de encaminhamentos de crianças e adolescentes para a Neurologia, evidenciando a magnitude do problema. Embora um tema da revisão teórica debata os fenômenos 
de neurocolonização, ou seja, as neurociências ocupando o lugar de fornecedora de elementos indispensáveis para se pensar a Educação, tais fenômenos não puderam ser reconhecidos na pesquisa documental.

As cartas-palavras falam de uma inespecificidade em termos de situação-problema para os quais é demandada a intervenção neurológica bem como uma hibridização de modos de olhar para as crianças descabentes. Coexistem, nessas cartas, menções a interferências e intervenções sobre os núcleos familiares, categorias diagnósticas psiquiátricas contemporâneas, o recurso a discursos psicologizantes como justificativas dos encaminhamentos para o "especialista no cérebro", (re)produzindo processos de medicalização que silenciam o diálogo pedagógico que poderia se constituir justamente como espaço de reconstrução da aprendizagem de seus sujeitos (CARVALHO, 2016).

[...] é preciso abertura para tratar com o pedagógico na medida em que se constitui enquanto espaço de constituição do ser. A escola e seus sujeitos precisam se sentir convidados ao encontro com uma forma de fazer-se presente na vida. O espaço existe, então, sejamos corajosos. (CARVALHO, 2016, p. 66).

Recolocar a pergunta sobre as expectativas em torno da intervenção do neurologista e ampliar as lentes com as quais se olha para essas crianças deve estar no horizonte de todos aqueles envolvidos no enfrentamento dos processos de redução dos fenômenos subjetivos a mero funcionamento cerebral. A função do cérebro é impulsionar o viver, jamais aprisioná-lo.

\section{REFERÊNCIAS}

ANGELUCCI, C. B. A patologização das diferenças humanas e seus desdobramentos para a educação especial. In: Reunião Nacional da ANPEd, 37., Florianópolis, 2015. Trabalho Encomendado GT15 - Educação Especial 1. Anais [...]. Florianópolis: UFSC, 2015.

CALIMAN, L. V. A constituição sócio-médica do "fato TDAH". Psicologia \& Sociedade, v. 21, n. 1, p. 135-44, abr. 2009.

CARVALHO, W. L. Experiência e cuidado de si: reflexões acerca do sujeito no espaço escolar. Cadernos de Pesquisa, v. 23, n. 3, p. 55, dez. 2016.

CASTEL, R. A ordem psiquiátrica: a Idade de Ouro do Alienismo. Rio de Janeiro: Graal, 1978.

CHRISTOFARI, A. C.; FREITAS, C. R. DE; BAPTISTA, C. R. Medicalização dos Modos de Ser e de Aprender. Educação \& Realidade, v. 40, n. 4, p. 1079-102, dez. 2015. 
COSTA, J. F. Ordem médica e norma familiar. Rio de Janeiro: Graal, 1979.

DE VOS, J. Deneurologizing Education? From Psychologisation to Neurologisation and Back. Studies in Philosophy and Education, v. 34, n. 3, p. 279-95, maio 2015.

DONZELOT, J. La police des familles. Paris: les Éditions de minuit, 2005.

FREITAS, C. R. DE. Corpos que não param: criança, "TDAH" e escola. Orientador: Claudio Roberto Baptista. 2011. 195f. Tese (Doutorado em Educação)- Universidade Federal do Rio Grande do Sul, Porto Alegre, RS, 2011.

GOODMAN, R.; SCOTT, S. Psiquiatria Infantil. São Paulo: Roca, 2004.

LANTERI-LAURA, G.; BOUTTIER, J.-G. La evolución de las ideas sobre el sistema nervioso central y sus relaciones con el desarrollo de la psiquiatría moderna. In: POSTEL, J.; QUÉTEL, C.; GONZÁLEZ ARAMBURO, F. Nueva historia de la psiquiatría. México: Fondo de Cultura Económica, 2000.

LAURIDSEN-RIBEIRO, E.; TANAKA, O. Y. Problemas de saude mental das crianças: abordagem na atenção básica. São Paulo: Annablume, 2005.

MOYSÉS, M. A. A. A institucionalização invisivel: crianças que não-aprendem-na-escola. São Paulo: FAPESP, 2001.

MOYSÉS, M. A. A. A medicalização na educação infantil e no ensino fundamental e as políticas de formação docente: a medicalização do não-aprender-na-escola e a invenção da infância anormal. In: REUNIÃO ANUAL DA ANPED, 31., 2008, Caxambu. Constituição brasileira, direitos humanos e educação. Anais [...]. Caxambu: ANPED, 2008.

PYKETT, J.; DISNEY, T. Brain-Targeted Teaching and the Biopolitical Child. In: KALLIO, K.; MILLS, S.; SKELTON, T. (Eds.). Politics, Citizenship and Rights. Geographies of Children and Young People. [s.I.] Springer Singapore, 2015. p. 1-17.

RICHTER, B. R. Hiperatividade ou indisciplina? - O TDAH e a patologização do comportamento desviante na escola. 2012. 126f. Orientador: Luíz Henrique Sacchi dos Santos. Dissertação (Mestrado em Educação e Ciências: Química da Vida e Saúde) Universidade Federal do Rio Grande do Sul. Porto Alegre: UFRGS, 2012.

ROSE, N. Beyond medicalisation. The Lancet, v. 369, n. 9562, p. 700-02, 2007.

ROSE, N. S.; ABI-RACHED, J. M. Neuro: the new brain sciences and the management of the mind. Princeton, N.J: Princeton University Press, 2013. 
SANTOS, L. H. S. O dispositivo de (bio)medicalização, as neurociências \& o currículo na produção de corpos medicalizados na escola contemporânea. In: PARAISO, M. A.; VILELA, R. A.; SALES, S. R. (Ed.). Desafios contemporâneos sobre currículo e escola básica. 1. ed. Curitiba: CRV, 2012. v. 1. p. 181-204.

SANTOS, L. H. S.; FREITAS, C. R. TDAH, educação e cultura: uma entrevista com llina Singh (Parte 1). Interface - Comunicação, Saúde, Educação, v. 20, n. 59, p. 1077-86, dez. 2016.

SINGH, I. Biology in context: social and cultural perspectives on ADHD. Children \& Society, v. 16, n. 5, p. 360-67, nov. 2002.

SURJUS, L.; CAMPOS, R. O. Deficiência Intelectual e Saúde Mental: quando a fronteira vira território. Rev. Polis e Psique, v. 3, p. 82-96, 2013.

ZORZANELLI, R. T.; ORTEGA, F.; BEZERRA JÚNIOR, B. Um panorama sobre as variações em torno do conceito de medicalização entre 1950-2010. Ciência \& Saúde Coletiva, v. 19, n. 6, p. 1859-68, jun. 2014.

\section{Sobre os autores:}

Ricardo Arantes - Mestre em Educação pela Universidade Federal do Rio Grande do Sul (UFRGS). Professor da Instituição Evangélica de Novo Hamburgo (IENH). E-mail: ricardolugon@gmail.com, Orcid: http://orcid.org/0000-0002-1826-6523

Claudia Freitas - Pós-doutora no campo da Educação Especial, na perspectiva inclusiva, na Universidade Federal do Rio Grande do Sul (UFRGS). Doutora em Educação pela UFRGS. Mestre em Educação pela Universidade do Vale do Rio dos Sinos (UNISINOS). Graduada em Psicopedagogia pela Escuela Psicopedagógica de Buenos Aires (EPsiBA), em Curso de Formación En Psicopedagogia Clínica. Professora na FACED/PPGEdu/UFRGS. Integrante do Núcleo de Estudos em Políticas de Inclusão Escolar NEPIE/FACED/UFRGS. E-mail: freitascrd@gmail.com, Orcid: http://orcid.org/0000-0002-7105-8539

\section{Recebido em dezembro de 2018 Aprovado em maio de 2019}


